\title{
Nylon 46-Polytetramethylene oxide segmented block copolymers
}

\author{
R. J. Gaymans, P. Schwering and J. L. de Haan \\ University of Twente, Department of Chemical Technology, PO Box 217. \\ 7500 AE Enschede, The Netherlands
}

(Received 15 September 1988; accepted 16 November 1988)

\begin{abstract}
Block copolymers were synthesized from amine-terminated polytetramethylene oxide (PMTO) $\left(\mathrm{M}_{w} 800\right.$ and 1130 ) and polyamide 4,6 salt. First prepolymers were prepared at $200-210^{\circ} \mathrm{C}$ in the presence of a solvent (pyrrolidone). The prepolymers were postcondensed at $255^{\circ} \mathrm{C}$ (where possible in the solid state) to a high molecular weight. In the materials the endgroups were analysed, and the inherent viscosities and ethanol extraction values measured. The thermal properties were determined with d.s.c. and d.m.a. With ethanol, polyether could be extracted. Thus it seems that not all the polyether is present as part of the block copolymer. Melt phasing seems to have taken place and occurs even more with the higher molecular weight PTMO. With d.m.a. two glass transitions were observed; one of the polyether phase and one of the polyamide-rich phase. The melting temperatures of these polyamide 4,6 block copolymers are high $\left(200-270^{\circ} \mathrm{C}\right)$, and the torsion modulus remained fairly constant up to these high melting temperatures.
\end{abstract}

(Keywords: Segmented block copolymer; polyether; polyamide; polyamide 4,6; d.s.c.; d.m.a.)

\section{INTRODUCTION}

Segmented block copolymers are multi-block copolymers which can be represented by the generalized formula $(-\mathrm{A}-\mathrm{B}-)_{n}$. These materials are of interest as thermoplastic elastomers if they are built up out of soft segments and hard segments. The soft segments have a low glass transition temperature; for these are often chosen the polyethers polypropylene oxide (PPOx), polytetramethylene oxide (PTMO) and aliphatic polyesters.

The hard segments are units which can crystallize and have a high melting temperature. For the hard segments the polyurethanes, polyesters and polyamides (PA) have been of most interest. These materials have been excellently reviewed ${ }^{1-7}$.

Of these copolymers the polyether-amide block copolymers combine good mechanical properties with a good performance at low temperatures. These systems phase separate easily which means that at least a three phase structure is formed: the amorphous soft polyetherrich, the amorphous polyamide-rich and the crystalline polyamide phase. If the polyether sometimes crystallizes like PTMO then four phases are present ${ }^{8-10}$. Due to the separation of the amorphous phases the composition of the phases remains fairly constant but the amounts vary and the polyether-rich soft phase keeps its low $T_{\mathrm{g}}$ over a wide range of concentrations. The hard polyamide phase contains little polyether so that the melting temperature and the high crystallization rate are better maintained.

The maximum use temperature of these systems is limited by the melting temperature. A high melting polyamide would have distinct advantages. There are several methods of synthesizing these polyether-amide block copolymers, resulting in amide, urethane, urea or ester linkages between the ether and amide segments ${ }^{5}$.

We studied the solution polymerization of amine terminated PTMO $\left(M_{\mathrm{n}} 800\right.$ and 1130) with nylon 46. 0032-3861/89/060974-04\$03.00

(C) 1989 Butterworth \& Co. (Publishers) Ltd.
Nylon 46 is a high melting and fast crystallizing polymer with excellent mechanical properties, particularly at high temperatures, excellent solvent resistance and good processability ${ }^{11}$ due to its structural regularity and its high amide content.

\section{EXPERIMENTAL}

\section{Materials}

Nylon 46 salt (pH 7.8) was prepared from adipic acid (Merck) and tetramethylene diamine (TMDA) (Merck) as described elsewhere ${ }^{11}$. PTMO amine terminated (BASF) bis-(3-aminopropyl)-polytetramethylene oxide molecular weights 1130 and 800, adipic acid (Merck) and pyrrolidone (Merck) were used as obtained.

Prepolymerization (50/50 composition): a 1.41 stainless steel Juvo autoclave, type 142, equipped with mechanical stirrer was charged with nylon 46 , salt $(266 \mathrm{~g})$, PTMO $(250 \mathrm{~g})$, adipic acid $(32.4 \mathrm{~g})$ and $550 \mathrm{~cm}^{3}$ pyrrolidone. After flushing the reactor with nitrogen a nitrogen starting pressure of 5 bar was used. The reactor with contents was warmed up in $30 \mathrm{~min}$ to $200-210^{\circ} \mathrm{C}$ and kept at that temperature for $30 \mathrm{~min}$ after which it was cooled and the pressure released. To remove the solvent the thick suspension was washed with water and dried.

Post condensation: the prepolymers were postcondensed in the solid state in a rotating glass reactor in an oven at $250-260^{\circ} \mathrm{C}$ in a stream of nitrogen for several hours.

\section{Characterization}

Viscometry. The $\eta_{\text {inh }}$ were determined on $1 \%$ solutions at $25^{\circ} \mathrm{C}$ with an Ubbelohde viscometer.

End group analysis. The amine end groups were determined potentiometrically on 100-150 mg samples in 
$35 \mathrm{~cm}^{3} 85 \%$ phenol with $0.1 \mathrm{M}$ trifluormethane sulphonic acid in tert.butanol.

The acid end groups were determined potentiometrically on 100-150 mg samples in $3 \mathrm{~g} o$-cresol and $35 \mathrm{~cm}^{3}$ benzyl alcohol with $0.1 \mathrm{M} \mathrm{KOH}$ in tert.butanol.

Ethanol extractions. The ethanol extraction content was determined on fine powder with a Soxhlet apparatus with ethanol refluxing for $16 \mathrm{~h}$.

Element analysis. The nitrogen content was determined on dried sample by element analysis.

D.s.c. analysis. The heats of fusion and the melting and crystallization temperatures were determined with a Perkin Elmer DSC-4 with a heating and cooling rate of $20^{\circ} \mathrm{C} \mathrm{min}^{-1}$. The peak maximum at the second warming up cycle was taken as the melting temperature. The heats of fusion were calculated on the polyamide fraction.

Dynamic mechanical analysis, With a Myrenne (ATM 3) torsion pendulum instrument the torsion moduli $G^{\prime}$ and $G^{\prime \prime}$ were analysed at a constant frequency of $1 \mathrm{~Hz}$ and a heating rate of $1^{\circ} \mathrm{C} \mathrm{min}^{-1}$. The $G_{\max }^{\prime \prime}$ is taken as $T_{\mathrm{g}}$.

\section{RESULTS AND DISCUSSION}

\section{Synthesis}

The nylon 46-PTMO segmented block copolymers were prepared from nylon 46 salt and amine terminated

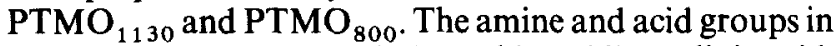
the reaction system were balanced by adding adipic acid. The copolymers were synthesized by a two step method, a prepolymerization with a solvent and a postcondensation in the solid state. The prepolymer was prepared at $200-210^{\circ} \mathrm{C}$, in presence of the solvent pyrrolidone. The reaction mass was washed with water and dried. The post-condensation was carried out at atmospheric pressure in a nitrogen atmosphere, for several hours at $255^{\circ} \mathrm{C}$. The influence of post condensation time was studied (Table 1).

The prepolymer (post-condensation time $0 \mathrm{~h}$ ) has a slight excess of amine groups. After condensing the end group concentrations decreased and the $\eta_{\mathrm{inh}}$ increased. In this way high molecular weight copolymers can be obtained.

A difficulty with the block copolymerization is the possible melt phase separation. To suppress this phase separation the prepolymerization was carried out in the presence of a solvent (pyrrolidone). To quantify the melt phase separation the polymers were extracted with ethanol. As can be seen from Table 1 the ethanol extraction content in the system with $\mathrm{PTMO}_{1130}$ and a

Table 1 Influence of postcondensation time. Prepolymer with $\mathrm{PTMO}_{1130}, 48 \% \mathrm{PA}$ and postcondensed at $255^{\circ} \mathrm{C}$

\begin{tabular}{lllll}
$\begin{array}{l}\text { Time } \\
\text { (h) }\end{array}$ & $\begin{array}{l}{\left[-\mathrm{NH}_{2}\right]} \\
(\mathrm{meq} / \mathrm{g})\end{array}$ & $\begin{array}{l}{[\mathrm{COOH}]} \\
(\mathrm{meq} / \mathrm{g})\end{array}$ & $\begin{array}{l}\eta_{\text {inh }} \\
(\mathrm{dl} / \mathrm{g})\end{array}$ & $\begin{array}{l}\text { EtOH solution } \\
(\%)\end{array}$ \\
\hline 0 & 0.330 & 0.325 & 0.32 & 50 \\
2.5 & 0.058 & 0.020 & 0.75 & - \\
5 & 0.039 & - & 0.94 & - \\
16 & 0.033 & 0.023 & 1.21 & 28 \\
29 & 0.033 & 0.002 & 1.31 & 27 \\
\hline
\end{tabular}

Table 2 Extraction. Amide content of a postcondensed sample, PTMO $_{1130}$ overall composition $48 \%$ PA, before extraction with ethanol, after extraction and in the extract

\begin{tabular}{lll}
\hline & $\begin{array}{l}\text { Nitrogen content } \\
(\%)\end{array}$ & $\begin{array}{l}\text { PA content } \\
(\%)\end{array}$ \\
\hline Post-condensed sample & $7.72 \pm 0.06$ & 51 \\
Extracted sample & $9.78 \pm 0.01$ & 66 \\
Extract $(28 w 0)$ & $1.70 \pm 0.05$ & 9 \\
\hline
\end{tabular}

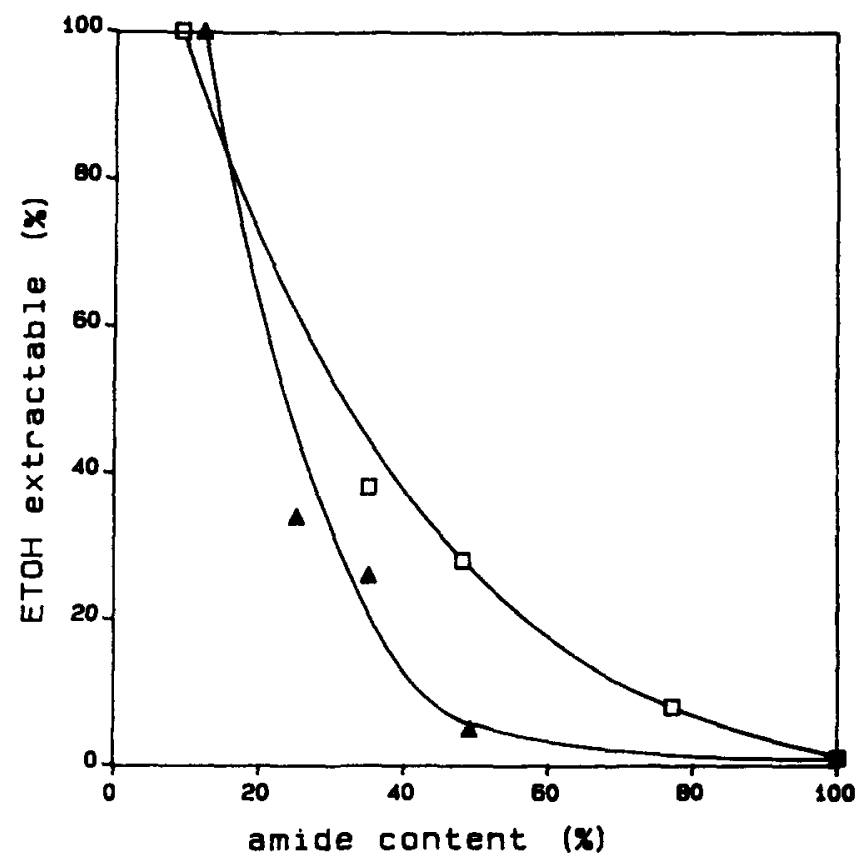

Figure 1 Ethanol extraction values as function of polyamide content; $\triangle$, PTMO $_{800} ;-\square-$, PTMO $_{1130}$

PA content of $48 \%$ was about $30 \%$. This is high. We analysed the polymer, the extracted polymer and the extract for their nitrogen content (Table 2).

The ethanol soluble extract had a nitrogen concentration, which corresponds to either the amine terminated PTMO or the PTMO-adipic acid polymer. The extract was rubbery and could be moulded. It thus seems to be the PTMO-adipic acid polymer.

The PA concentration in the extracted polymer is $66 \%$. This is in agreement with what would be expected. Thus it seems that not withstanding the presence of the pyrrolidone during the prepolymerization, phase separation has taken place and part of the PTMO is not built into the block copolymer.

The ethanol extraction content was also studied as function of the overall composition (Figure 1). From nylon 46 only $1 \%$ could be extracted, but the PTMO-adipic acid polymer was completely soluble.

Lower extraction values could be obtained if the $\mathrm{PTMO}_{800}$ was used instead of PTMO ${ }_{1130}$ (Figure 1). The $50 / 50$ sample had now an extractable content of only $5 \%$ and the PTMO-adipic acid polymer was completely soluble. This also suggests that what is extracted is the PTMO-adipic acid polymer which has phase separated during the prepolymerization. This phase separation can be suppressed by prepolymerization with a better solvent system and/or by lowering the molecular weight of the PTMO. 
Table 3 Properties PTMO $_{1130}$ block copolymers

\begin{tabular}{ccccccc}
\hline $\begin{array}{l}\text { PA } \\
(\%)\end{array}$ & $\begin{array}{l}\text { Extractable } \\
(\%)\end{array}$ & $\begin{array}{l}T_{\mathrm{a}} \\
\left({ }^{\circ} \mathrm{C}\right)\end{array}$ & $\begin{array}{l}T_{\mathrm{c}} \\
\left({ }^{\circ} \mathrm{C}\right)\end{array}$ & $\begin{array}{l}\Delta H_{\mathrm{a}} \\
\left(\mathrm{J} / \mathrm{g}_{\mathrm{PA}}\right)\end{array}$ & $\begin{array}{l}T_{\mathrm{g} \text { (PMTO })} \\
\left({ }^{\mathrm{g}} \mathrm{C}\right)\end{array}$ & $\begin{array}{l}T_{\mathrm{g}(\mathrm{PA})} \\
\left({ }^{\circ} \mathrm{C}\right)\end{array}$ \\
\hline 100 & 1 & 289 & 257 & 84 & - & 80 \\
77 & 8 & 270 & 233 & 78 & -75 & 65 \\
$66^{*}$ & 0 & 269 & 234 & 77 & -70 & 52 \\
48 & 28 & 268 & 231 & 60 & -70 & 50 \\
35 & 38 & 258 & 217 & 60 & -70 & 40 \\
9 & 100 & - & - & - & -65 & - \\
\hline
\end{tabular}

* Extracted sample

Table 4 Properties PTMO $_{800}$ block copolymers

\begin{tabular}{rcccccc}
\hline $\begin{array}{l}\text { PA } \\
(\%)\end{array}$ & $\begin{array}{l}\text { Extractable } \\
(\%)\end{array}$ & $\begin{array}{l}T_{\mathrm{a}} \\
\left({ }^{\circ} \mathrm{C}\right)\end{array}$ & $\begin{array}{l}T_{\mathrm{c}} \\
\left({ }^{\circ} \mathrm{C}\right)\end{array}$ & $\begin{array}{l}\Delta H_{\mathrm{a}} \\
\left(\mathrm{J} / \mathrm{g}_{\mathrm{PA}}\right)\end{array}$ & $\begin{array}{l}T_{\mathrm{g} \text { (PMTO })} \\
\left({ }^{\circ} \mathrm{C}\right)\end{array}$ & $\begin{array}{l}T_{\mathrm{g}(\mathrm{PA})} \\
\left({ }^{\circ} \mathrm{C}\right)\end{array}$ \\
\hline 100 & 1 & 289 & 257 & 84 & - & 80 \\
49 & 5 & 265 & 227 & 69 & -70 & 50 \\
35 & 26 & 248 & 212 & 31 & -70 & 50 \\
25 & 34 & 196 & 148 & 21 & -70 & 50 \\
12 & 100 & - & - & - & -70 & - \\
\hline
\end{tabular}

\section{Properties}

The melting temperatures of the block copolymers decrease gradually with the lowering of the polyamide content. This is marked for the $25 \%$ polyamide system (Tables 3 and 4). The lowering of the melting temperature of block copolymers has been explained as a decrease in lamellar thickness as a consequence of a decrease in polyamide block length ${ }^{6,9}$.

For these multi-phase systems it is difficult to determine the polyamide block length and whether this is the sole cause for the lowering of the melting temperature. The temperature difference between the melting and crystallization temperature is similar to the low amide samples which are all in the order of $34-37^{\circ} \mathrm{C}\left(T_{\mathrm{a}}-T_{\mathrm{c}}\right)$, which means that they all crystallize nearly as fast from the melt as nylon 46 . As expected, the $48 \%$ PA sample injection moulded well.

There is little decrease in the heat of fusion calculated on the polyamide phase in the high amide content samples. The decrease is greater with the lower amide concentrations and was absent in the PTMO-adipic acid polymer. The order in the polyamide phase is unaffected by the block length unless the block length becomes very small, in agreement with the results of Goldbach ${ }^{9}$.

The results of the dynamic mechanical analysis of the samples are given in Figures 2 and 3. With both the block copolymers with $\mathrm{PTMO}_{1130}$ and $\mathrm{PTMO}_{800}$ two glass transitions are observed. One is at $-70^{\circ} \mathrm{C}$ for the polyether blocks and is independent on composition and block length. The second transition is at $80-50^{\circ} \mathrm{C}$ for the PA blocks which decreases with increasing polyether content. Here too the polyether block length seems to have little effect. Even in an extracted sample these two glass transitions are present. This suggests that there is a PTMO amorphous phase, a PA-rich amorphous phase and a PA crystalline phase next to an extractable PTMO-adipic acid phase. On top of that the PTMO PT130 $_{13}$ has a broadening at the high temperature side of its glass transition suggesting crystallization of the PTMO. The rubber plateau reaches up to the melting temperature of the block copolymer.
The torsion moduli of wetted samples $\left(\mathrm{PMTO}_{1130}\right.$. $46 \%$ PA) are given in Figure 4. As expected the glass transition of the PA rich phase is lowered to below room temperature while the transition temperature of the PTMO-phase is unaffected.

If nylon 46-PTMO is compared with a nylon 6 based segmented block copolymer (Figure 5) it can be seen that the PTMO polymers have a shear modulus $\left(G^{\prime}\right)$ which is less sensitive to the temperature and melt at a higher temperature above room temperature.

\section{CONCLUSIONS}

Nylon 46-PTMO segmented block copolymers can be synthesized to a high molecular weight by a two-step process; a solution prepolymerization at $200-210^{\circ}$ in an autoclave and a post-condensation in the solid state. Although the prepolymerization was carried out with a solvent for the starting materials, a considerable amount of nylon-free-PTMO (ethanol extractable) was present. This suggests that during the prepolymerization the reaction mixture was already phase separated. This phase separation was less at the higher amide concentrations and with the lower molecular weight PTMO.

The order and melting temperature of the polyamide phase of the $66 \%$ PA samples is somewhat lower than those of the neat nylon and they decrease at lower amide concentrations.

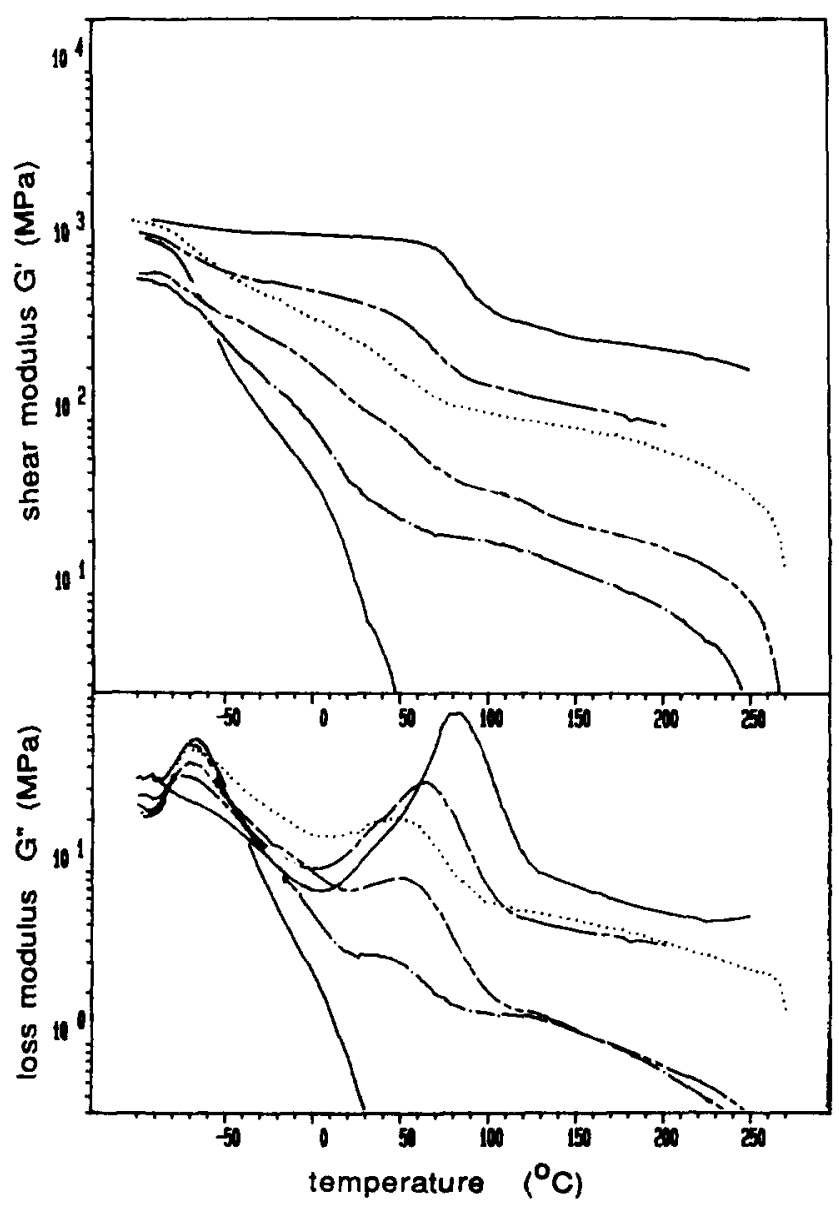

Figure 2 Shear and loss moduli as function of temperature at $1 \mathrm{~Hz}$ Nylon 46-PTMO ${ }_{1130}$, influence of composition; - _, $100 \% \mathrm{~N} 46$;

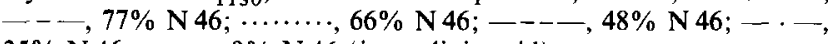
$35 \% \mathrm{~N} 46 \_-9 \% \mathrm{~N} 46$ (just adipic acid) 


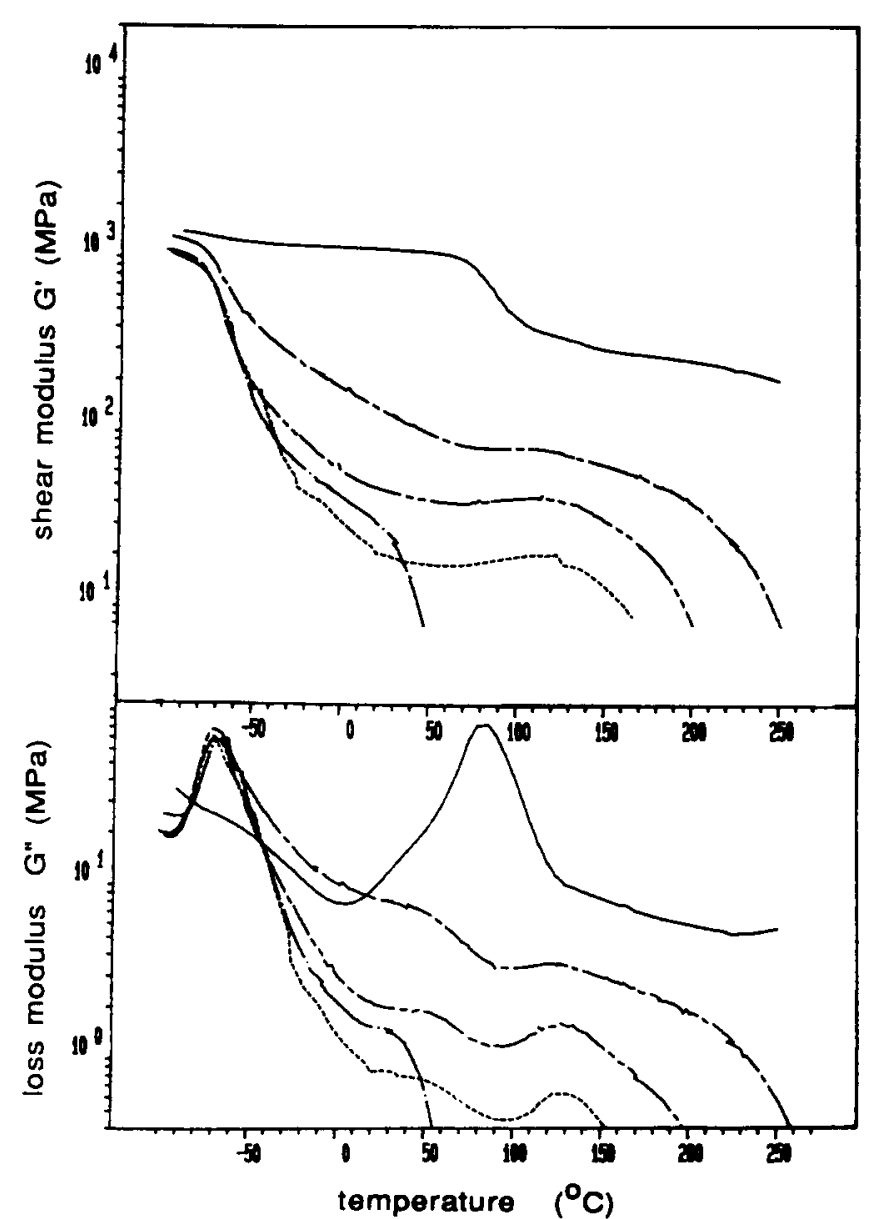

Figure 3 Shear and loss moduli as function of temperature at $1 \mathrm{~Hz}$, Nylon 46-PTMO ${ }_{800}$, influence of composition;,$- 100 \% \mathrm{~N} 46$; $\ldots-\ldots, 49 \% \mathrm{~N} 46 ; \ldots \ldots, 35 \% \mathrm{~N} 46 ; \ldots \ldots \ldots, 25 \% \mathrm{~N} 46 ; \ldots .-$, $12 \%$ N 46 (just adipic acid)

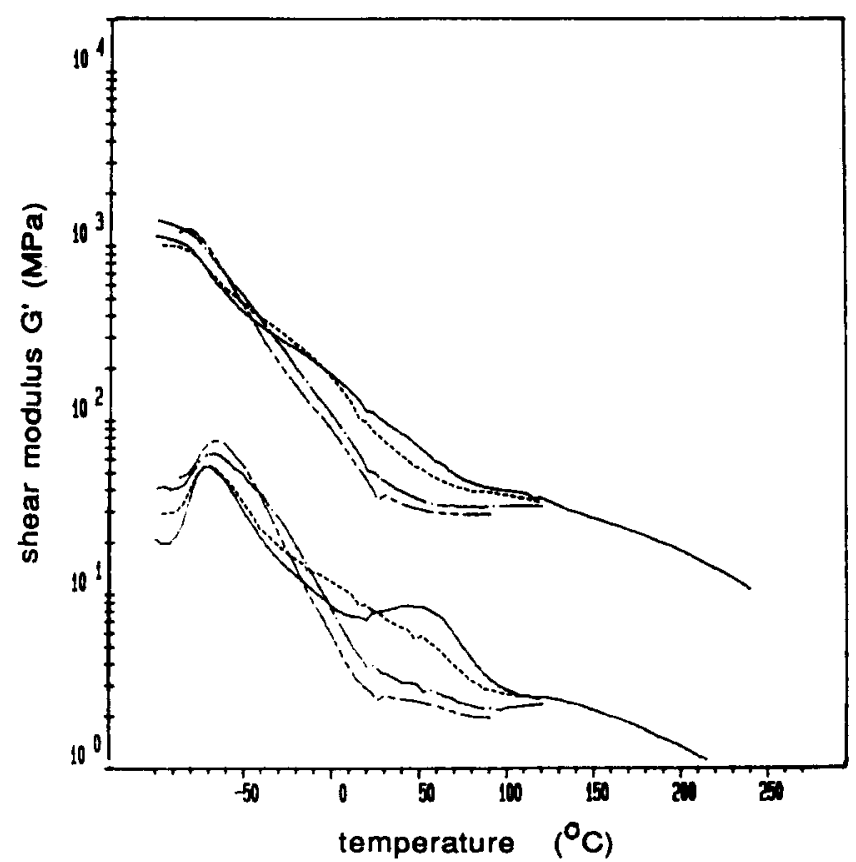

Figure 4 Shear modulus as function of temperature, at $1 \mathrm{~Hz}$, Nylon $46-\mathrm{PTMO}_{1130}, 46 \% \mathrm{~N} 46$, influence of water content; —_, dry; ......., $1 \% ;-.-, 5 \% ;---, 9 \%$

The DMA-results show that the shear modulus is fairly constant over a wide temperature range and that the value is dependent in the composition. Water seems to have only a small effect on the properties. The torsion proper-

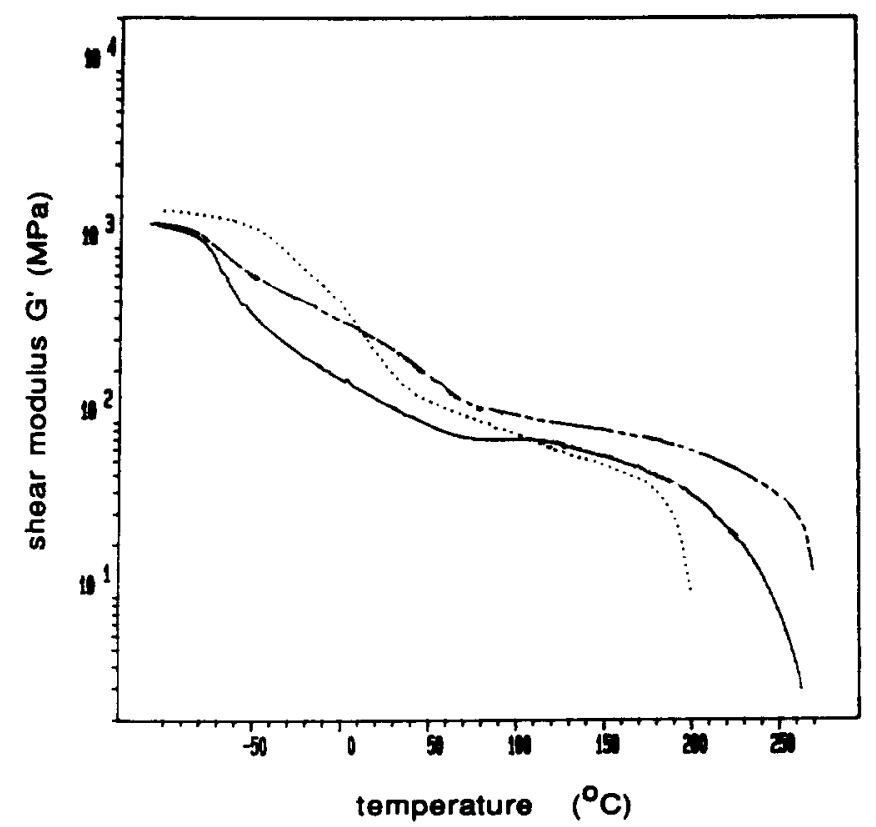

Figure 5 Shear modulus as function of temperature at $1 \mathrm{~Hz}$, a comparison; - - - , Nylon 46-PMTO ${ }_{1130}, 66 \%$ N 46; _ _ Nylon $46-\mathrm{PTMO}_{800}, 49 \% \mathrm{~N} 46 ; \cdots \cdots \cdots$, PEBAX 55D (ATO CHEM)

ties of these PTMO-nylon 46 polymers compare well with those of industrial polyamide segmented block copolymers.

\section{ACKNOWLEDGEMENTS}

This work is part of the research programme of the University of Twente and was supported financially by DSM Research, The Netherlands. The authors wish to thank Ing. J. van der Loos (DSM/TUE) and Dr E. Roerdink (DSM) for their active interest in the project.

\section{REFERENCES}

1 Schroeder, H. and Cella, R. J. in 'Encyclopedia of Polymer Science and Engineering', Vol. 12, 2nd edn, Wiley, London, 1988 , p. 75

2 Meckel, W., Goyert, W. and Wieder, W. in 'Thermoplastic Elastomers', (Eds N. R. Legge, G. Holden and H. E. Schroeder), Hanser, Munich, 1987, Ch. 2

3 Adams, R. K. and Hoeschele, G. K. in 'Encyclopedia of Polymer Science and Engineering', Vol. 12, 2nd edn, Wiley, London, 1988, Ch. 8

4 Nelb, R. C., Chen, A. T. and Onder, K. in 'Encyclopedia of Polymer Science and Engineering', Vol. 12, 2nd edn, Wiley, London, 1988, Ch. 9A

5 Deleens, G. in 'Encyclopedia of Polymer Science and Engineering', Vol. 12, 2nd edn, Wiley, London, 1988, Ch. 9B

6 Wegner, G. in 'Encyclopedia of Polymer Science and Engineering', Vol. 12, 2nd edn, Wiley, London, 1988, Ch. 12, section 5

van Berkel, R. W. M., de Graaf, S. A. G., Huntjens, F. J. and Vrouwenreats, C. M. F. in 'Developments in Block Copolymers', Vol. 1, (Ed. I. Goodman), Applied Science Publishers, London, 1982, Ch. 7

8 Bornschlegl, E., Goldbach, G. and Meyer, K. Progr. Colloid and Polymer Sci. 1985, 71, 119

9 Goldbach, G., Kita, M., Meyer, K. and Richter, K. P.Progr. Colloid and Polymer Sci. 1986, 72, 83

10 Lomar, J. and Meyer, K. Makromol. Chem., Macromol Symp. $1988,16,161$

11 Gaymans, R. J., van Utteren, T. E. C., van den Berg, J. W. A. and Schuijer, J. J. Polym. Sci., Polym. Chem Edn. 1977, 15, 537 